\title{
Correction to: Integrated device for colorimetric detection of arsenite using polyethylene glycol capped gold nanoparticles-Lab-on-chip
}

\author{
Shalvi ${ }^{1} \cdot$ Nitesh Kumar $^{2} \cdot$ Kanak Lata Verma $^{3} \cdot$ Vinod Kumar Jain $^{2} \cdot$ Suman Nagpal ${ }^{2}$
}

Published online: 25 August 2021

(c) Korean Society of Environmental Risk Assessment and Health Science 2021

\section{Correction to: Toxicology and Environmental Health Sciences https://doi.org/10.1007/s13530-021-00095-5}

Due to an unfortunate oversight during the correction process, the figures as well as the author name from Shalvi have not been updated.

The author name Shalvi Sharma should be read Shalvi.

The correct figures are as given below (Figs. 2, 5, 6):

The original article has been updated.

The original article can be found online at https://doi.org/10.1007/ s13530-021-00095-5.

Suman Nagpal

snagpal@amity.edu

1 Amity Institute of Forensic Sciences, Amity University,

Noida, Uttar Pradesh 201303, India

2 Amity Institute for Advanced Research and Studies (Materials and Devices), Amity University, Noida, Uttar Pradesh 201303, India

3 Regional Forensic Science Laboratory, Home Department, GNCT of Delhi, Chanakyapuri, New Delhi 110021, India 

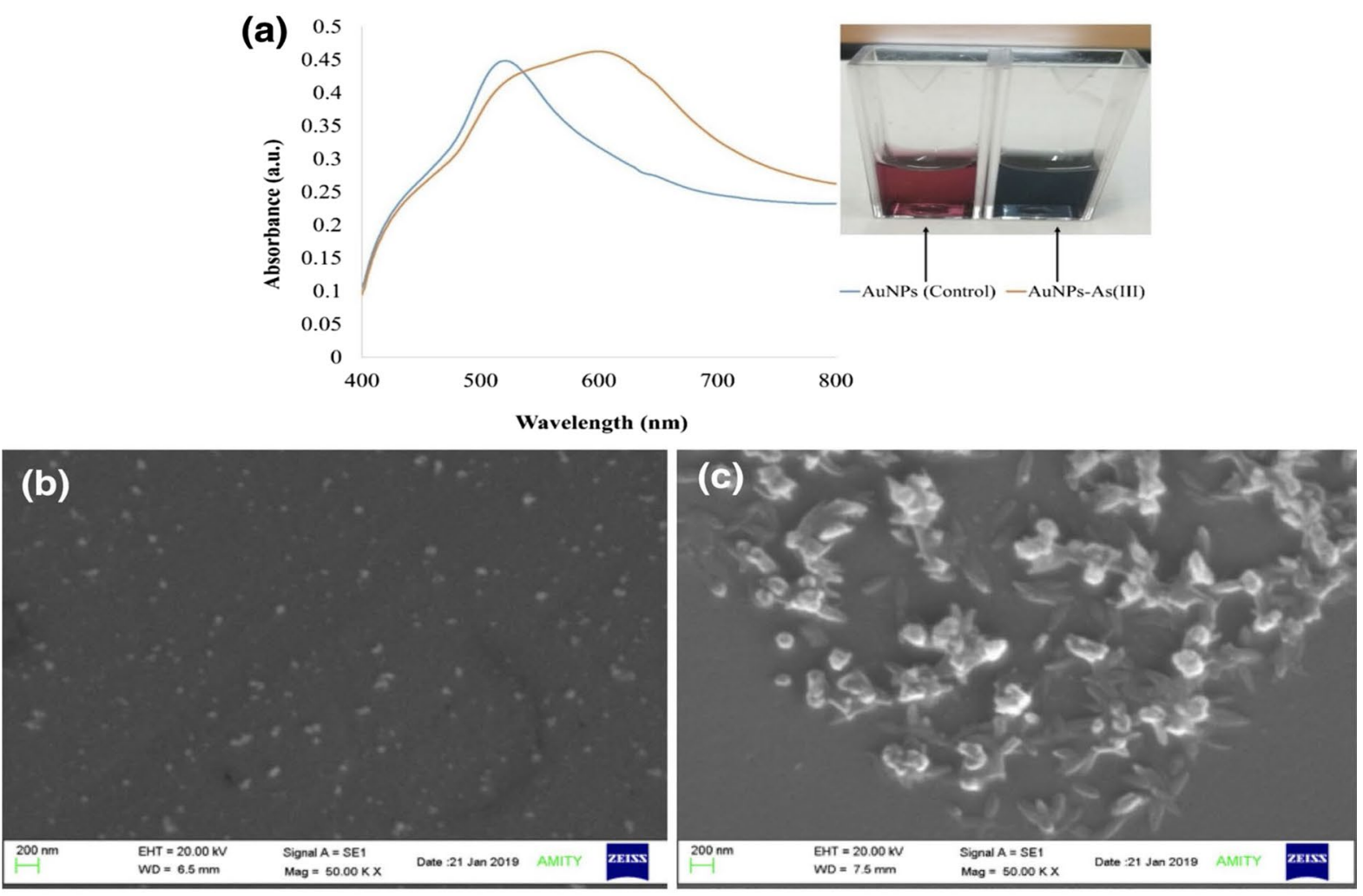

(d)
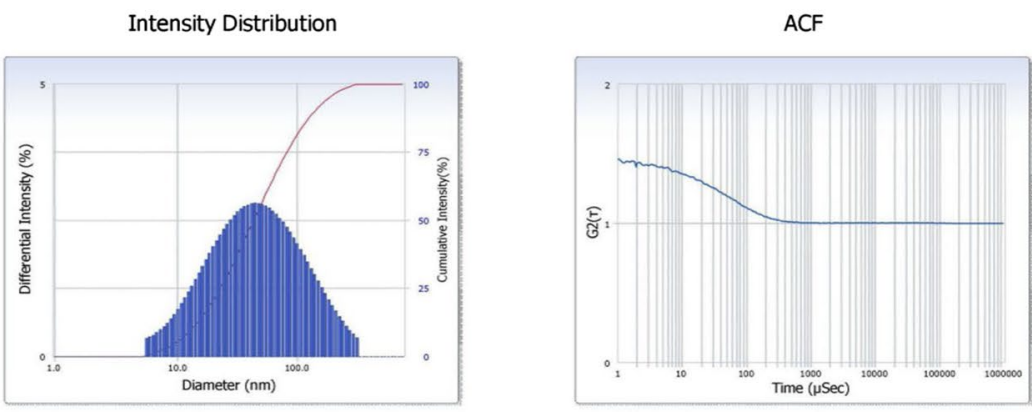

\begin{tabular}{|c|c|c|c|c|c|}
\hline \multicolumn{3}{|c|}{ Distribution Results (Contin) } & \multicolumn{3}{|l|}{ Cumulants Results } \\
\hline Peak & Diameter $(\mathrm{nm})$ & Std. Dev. & \multicolumn{3}{|c|}{ Polydispersity Index (P.I.) : 0.243} \\
\hline 1 & 67.7 & 61.0 & Diffusion Const. & $: 1.171 \mathrm{e}-007$ & $\left(\mathrm{~cm}^{2} / \mathrm{sec}\right)$ \\
\hline 2 & 0.0 & 0.0 & & & \\
\hline 3 & 0.0 & 0.0 & \multicolumn{3}{|l|}{ Measurement Condition } \\
\hline 4 & 0.0 & 0.0 & Temperature & $: 25.0$ & $\left({ }^{\circ} \mathrm{C}\right)$ \\
\hline 5 & 0.0 & 0.0 & Diluent Name & : WATER & \\
\hline \multirow[t]{2}{*}{ Average } & 67.7 & 61.0 & Refractive Index & $: 1.3328$ & \\
\hline & & & Viscosity & $: 0.8878$ & (cP) \\
\hline Residual & $7.315 \mathrm{e}-003$ & $(O . K)$ & Scattering Intensity & $\begin{array}{l}: 19055 \\
: 1407\end{array}$ & (cps) \\
\hline
\end{tabular}

Fig. 2 a UV-visible spectroscopy spectra of PEG-AuNPs with As (III); b scanning electron microscopy images of bare PEG-AuNPs; $\mathbf{c}$ PEGAuNPs with As (III); d dynamic light scattering of bare PEG-AuNPs 

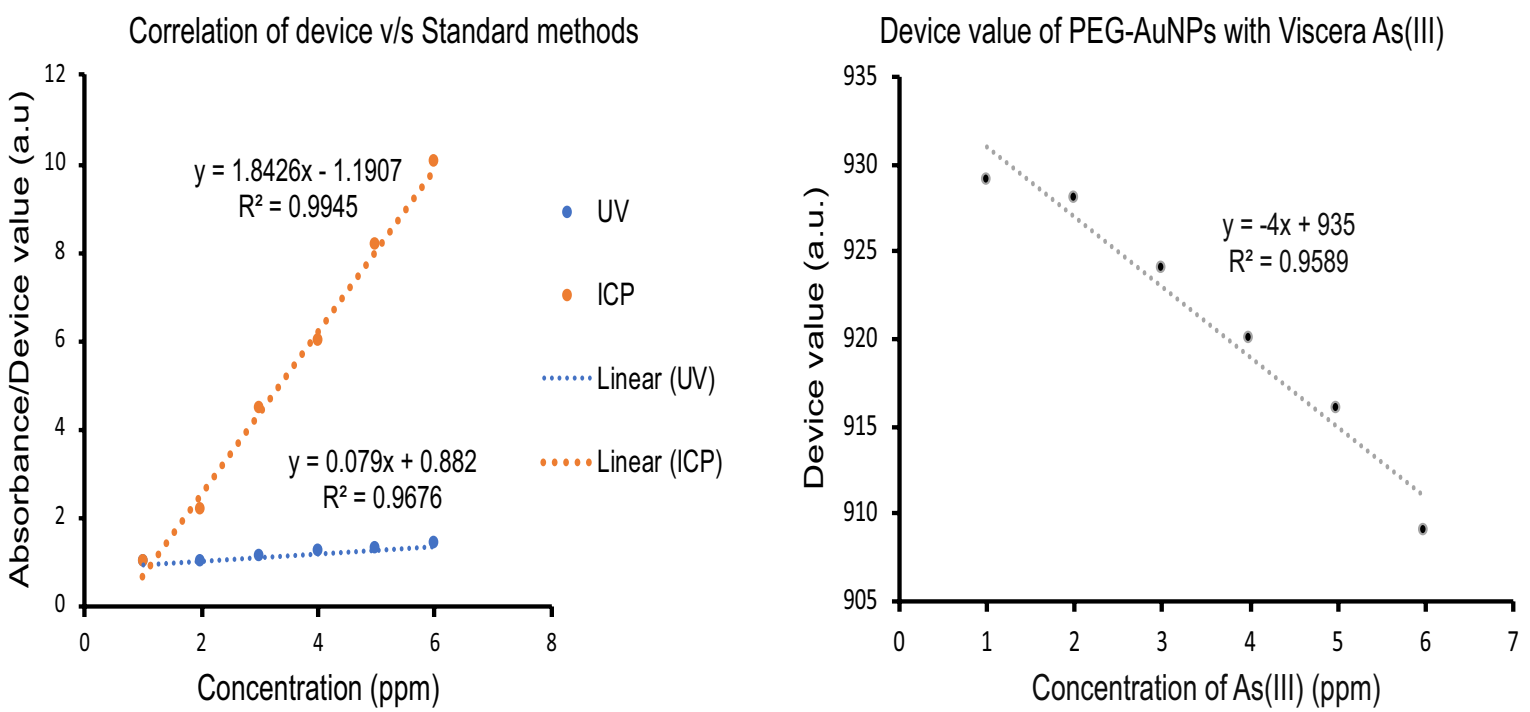

Fig. 5 Correlation graph showing relative observation of As (III) in tissue samples via UV-Vis, ICP-OES and fabricated hand-held device

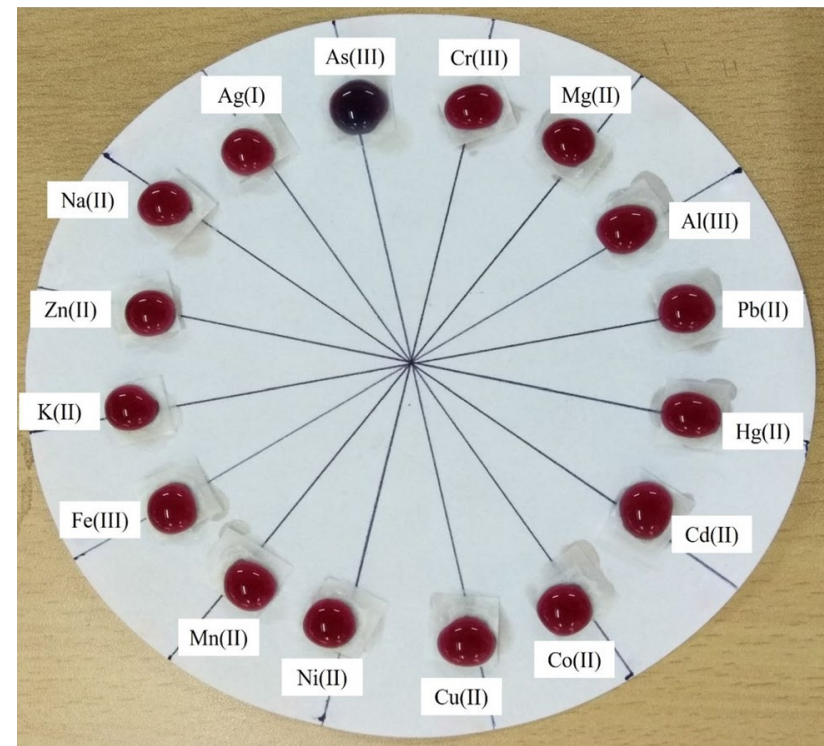

Fig. 6 Circular representation of interference study of PEG-AuNPs towards other toxic metal ions with reference to As (III) 